\title{
3D Printing of Aramid Nanofiber Composites by Stereolithography
}

Sachini D. Perera, Alejandra Durand-Silva, Ashele K. Remy, Shashini D. Diwakara, Ronald A. Smaldone*

Department of Chemistry and Biochemistry, University of Texas at Dallas, 800 West Campbell Road, Richardson, Texas 75080, United States

KEYWORDS 3D printing, Additive manufacturing, Vat photopolymerization, Nano composites, Aramid nanofibers

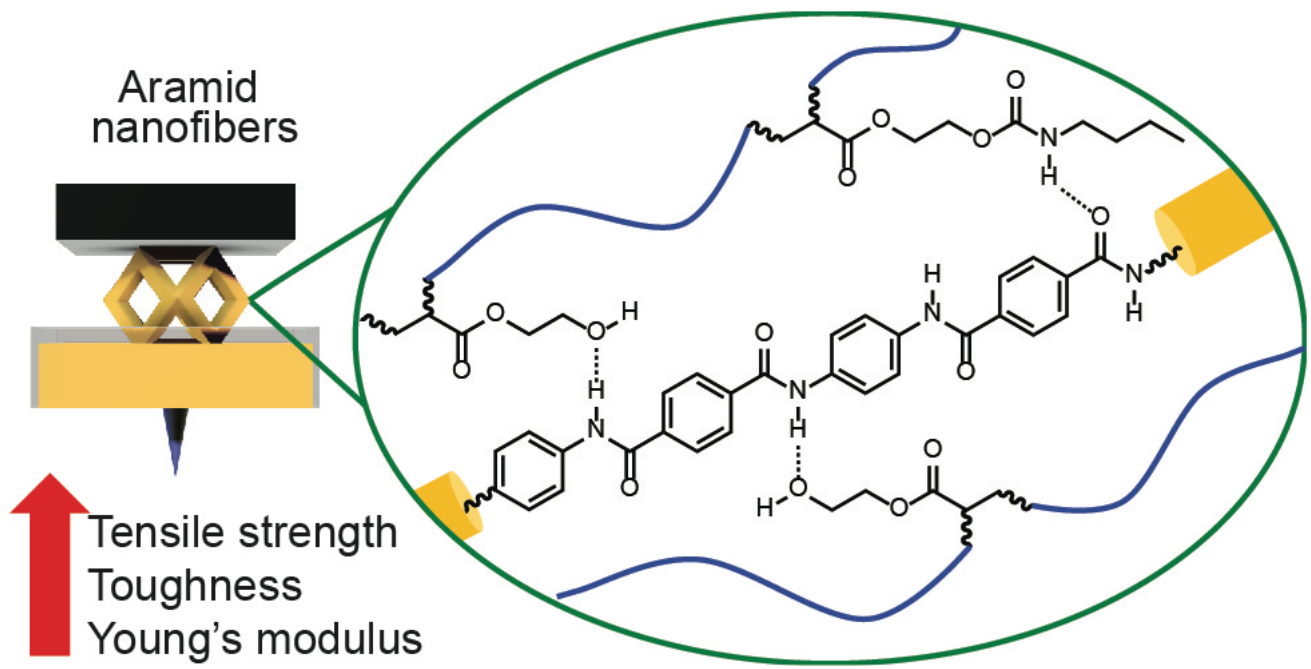

ABSTRACT: Vat photopolymerization is a versatile 3D printing method that produces parts using polymeric materials with uniform mechanical properties, high quality surface finish and highresolution features. However, it is challenging to make composite materials with vat photopolymerization mainly due to the imperfect filler dispersion in the photo resin. Herein, we describe a methodology to incorporate aramid nanofibers (ANFs) into a 3D printable photoresin as a dispersion, followed by a solvent exchange process that limits anisotropic shrinkage and cracking of the printed polymer. By incorporating $0.60 \mathrm{wt} \%$ of ANFs, both the tensile strength and toughness increased by $264 \%$ and $219 \%$ respectively, while the Young's modulus had a 406 $\%$ increase compared to the control photoresin. 


\section{Introduction}

Additive manufacturing (also known as 3D printing) is a process which creates 3D objects by adding materials in a layer-by-layer fashion from computer-aided designs (CAD). ${ }^{1}$ Highly complex and customized structures can be produced without the need for expensive conventional molds or generating the waste created by subtractive manufacturing methods such as milling. ${ }^{2,3}$ Vat photopolymerization 3D printing technologies have gained broad attention recently due to their ability to offer high resolution and rapid fabrication speeds. ${ }^{4,5}$ Stereolithography (SLA) is a vat photopolymerization method that typically uses acrylate-based resins containing a photo initiator and uses a laser as a light source to activate photopolymerization. ${ }^{6-8}$ This technique has many advantages including the ability to produce high quality objects at resolutions as small as 10 $\mu \mathrm{m}$ with a smooth surface finish. ${ }^{5}$ Photoresins for SLA should contain monomers or oligomers that are in the liquid state, polymerize rapidly upon exposure to light, and have viscosities lower than $10 \mathrm{~Pa} \cdot \mathrm{s}^{9}$ Many resins have not met the requirements of industrial manufacturing applications due to insufficient thermal and mechanical properties of the printed parts and challenges in resin formulation..$^{5,10}$

Significant effort has been devoted to improving the mechanical properties of 3D printed materials and composites are playing a major role in this endeavor. ${ }^{11-15}$ Composites are desirable because different types of additives can be mixed with low cost and scalable polymer matrices to produce materials with a wide variety of properties without the need to redesign the polymer structure for each application. When compared to conventional microscale composite fillers, nanocomposite reinforcements are especially useful as their smaller size enables a greater interaction area with the surrounding polymer matrix, thereby more effectively transferring stress between the filler and the matrix. ${ }^{16}$ The properties of bulk nanocomposites depend on the type of nanoscale filler, and the types of interactions that can occur between the polymer matrix and the surface of the fillers. Different types of nanofillers (e.g., cellulose nanocrystals, ${ }^{17-20}$ carbon nanotubes, ${ }^{21-23}$ graphene oxide ${ }^{24-26}$ ) have been used to improve mechanical, thermal and electrical properties as well as to introduce new functions to the polymer composites. However, even though many different polymeric nanocomposites have been produced, only a few have been used in extrusion-based 3D printing ${ }^{13,24,27}$ and even fewer with vat photopolymerization methods. ${ }^{14,28}$ One of the main challenges in printing composites with vat photopolymerization is the difficulty in formulating homogeneous photoresins. In many cases, increasing the nano-filler loading can result in phase separation, agglomeration, voids, and high viscosities. ${ }^{16}$ Thus, it is essential to develop new methods to produce photo-printable composite resins that avoid these issues.

Kevlar fibers formed from poly(paraphenylene terephthalamide), commonly known as aramid nanofibers (ANFs), are a useful nanofiller ${ }^{29}$ to improve the mechanical properties of polymer composites. ANFs can have strong intermolecular interactions such as hydrogen bonding, aromatic and van der Waals interactions with the surrounding polymer matrix, which lead to their exceptional strength and stiffness. ${ }^{30}$ ANFs are prepared by treating industrially produced Kevlar in a basic solution which enables the disruption of the hydrogen bonding network as well as partial hydrolysis of the amide linkages, resulting in rigid and nanometer sized polymeric fibers. This solution can be used as a dispersion in a solvent or to obtain ANF pulp by precipitating the fibers from these solutions. Previous work has shown that a small amount of ANFs in a polymer matrix 
can significantly enhance its mechanical properties, such as tensile strength, ${ }^{30-34}$ Young's modulus, ${ }^{31,32}$ and toughness. ${ }^{30,34}$

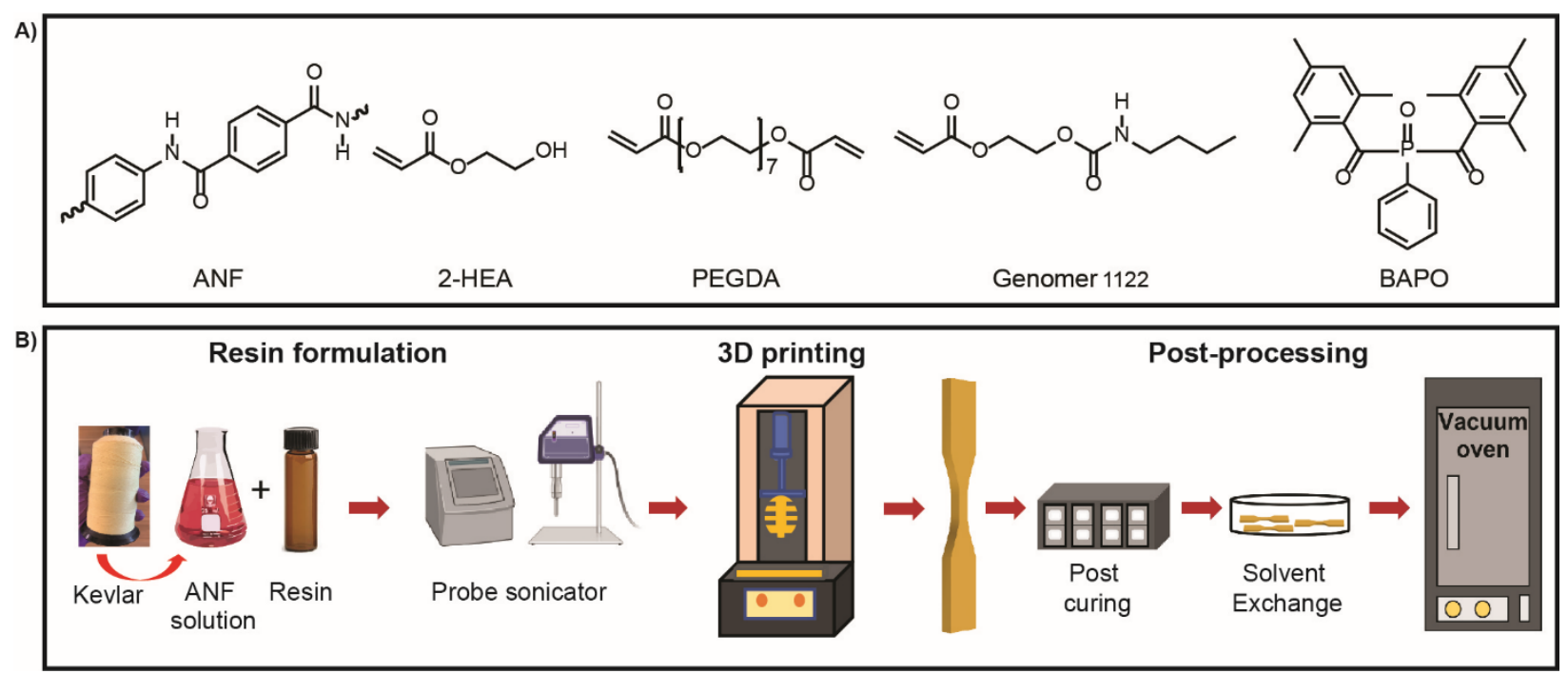

Figure 1. (A)Molecular structures of the components used for the formulation of an ANF containing photoresin (B) A schematic diagram for the steps followed for the nano filler preparation, photoprinting and post processing procedures followed for the printed nanocomposites in this study.

In addition to improved mechanical strength, ANF composites are useful for a variety of applications including biomedical technologies, ${ }^{35}$ water purification, ${ }^{36}$ and even as materials with advanced infrared adsorption properties. ${ }^{37}$ Yet, 3D printed ANF composites are still uncommon, ${ }^{38}$ likely due to the difficulties of incorporating ANFs into printable, homogeneous resin mixtures. In this work, we designed an ANF containing photoresin that is compatible with SLA printing. To make a homogeneous system, we added ANFs to the resin as a solution in dimethyl sulfoxide (DMSO) and optimized a post-print processing method to remove the solvents to make crack-free parts while retaining their shape and resolution. We show that the addition of ANFs can increase the toughness and ultimate tensile strength of the printed parts.

\section{EXPERIMENTAL SECTION}

\subsection{Materials}

All chemicals are used as received unless otherwise not-ed. 2-hydroxyethyl acrylate (2-HEA, $>95 \%$, stabilized with MEHQ), Phenylbis (2,4,6- trimethylbenzoyl) phosphine oxide (BAPO, $>96 \%$ ) were purchased from TCI. Polyethylene glycol diacrylate (PEGDA - weight average molecular weight $=430 \mathrm{~g} / \mathrm{mol}$ ) was supplied by MP Bio-medicals LLC and Genomer® 1122 was supplied as a sample by Rahn USA Corp and used as received. Poly (paraphenylene terephthalamide) (PPTA) thread was obtained from DuPont. Dimethyl sulfoxide (DMSO, 99.7\%) and potassium hydroxide $(\mathrm{KOH})$ were purchased from Fisher Scientific. 


\subsection{Preparation of Photoresin - ANF nanocomposites}

A 2 wt.\% ANF solution in DMSO was prepared as previously described. ${ }^{39}$ Photoresins with different concentrations of ANFs were prepared by mixing 2-HEA, Genomer 1122, and PEGDA (Figure 1A) according to Table $\mathrm{S} 1 \mathrm{in} 40 \mathrm{ml}$ amber glass vials, and vortexed for $5 \mathrm{~min}$. Afterwards, the previously prepared $2 \mathrm{wt} . \%$ ANF/DMSO dispersion was added according to Table S1. All the formulations were then mixed using a probe sonicator for $60 \mathrm{~s}$ at $60 \mathrm{~W}$. Photoinitiator (BAPO) was added, and the formulations were sonicated again for $1 \mathrm{~h}$ in a bath ultrasonicator. The prepared controls and the ANF formulations were printed using a Form2 SLA 3D printer (FormLabs, Somerville, MA, USA).

\subsection{D printing and Post-Processing}

For the controls and ANF composites, ASTM D638 type V standard tensile specimens were printed in open mode, at a resolution of $100 \mu \mathrm{m}$, at room temperature $\left(25^{\circ} \mathrm{C}\right)$. The SLA printer vat was modified using silicone molds (5.25 x $1.25 \times 1.25$ inches) to print using smaller volumes. Small vats were fabricated on a borosilicate glass plate and the bottom of the silicone mold was coated with polydimethylsiloxane elastomer (SYLGARD® 184, Dow Chemical Co.). After printing, the specimens were washed with iso-propanol to remove any unreacted monomers, and dried under dynamic vacuum for $6 \mathrm{~h}$ at $25^{\circ} \mathrm{C}$. These samples were post cured at $405 \mathrm{~nm}$ for $1 \mathrm{~h}$. Then the samples were immersed in Petri dishes containing deionized (DI) water for $12 \mathrm{~h}$ to remove the DMSO, replacing the water every $3 \mathrm{~h}$. Finally, the specimens were left to dry at ambient temperature and pressure for $24 \mathrm{~h}$ and then in the vacuum oven at $80^{\circ} \mathrm{C}$ for $12 \mathrm{~h}$, prior to characterization. (Figure 1B)

2.4. Mechanical, Thermal and Morphological Characterization of ANF Reinforced Nanocomposites

Tensile tests were performed in ASTM D638 type V specimens, at $25^{\circ} \mathrm{C}$ using an Instron 5848 Micro Tester (Illinois Tool Works, Inc., Norwood, MA, USA), with a $50 \mathrm{~N}$ load cell, at an extension rate of $10 \mathrm{~mm} / \mathrm{min}$. Stress - strain curves were used to determine ultimate tensile strength (UTS), strain at break, Young's modulus and toughness as an average of three specimens for each formulation with a standard deviation. For swelling tests, ANF nanocomposite resins and the control resin formulations were printed into rectangular prisms $\left(\begin{array}{lll}15 & 10 & 1.5\end{array} \mathrm{~mm}^{3}\right)$ and post processed as described in the previous section. Next, the samples were kept in the vacuum oven for $24 \mathrm{~h}$ at $80^{\circ} \mathrm{C}$ to get the weight measurement $\mathrm{W} 1$, then immersed in water for $24 \mathrm{~h}$ to get $\mathrm{W} 2$. The calculations were done using these weight measurements with five specimens for each formulation (Eq 1, Table S2). Tests were done to evaluate dimensional stability before and after post-processing. For this, rectangular prisms $\left(\begin{array}{lll}15 & 10 & 1.5 \mathrm{~mm}^{3}\end{array}\right)$ were $3 \mathrm{D}$ printed and the initial length (LI), width (WI), and the thickness (TI) were measured using a Vernier caliper. After postprocessing steps were carried out, the final measurements were taken as final length (LF), final width (WF), and final thickness (TF). Calculations (Eq 2) were done to study the shape stability of printed rectangular prisms (Figure S1).

Degree of swelling $(\%)=(\mathrm{W} 2-\mathrm{W} 1) / \mathrm{W} 1 * 100(\mathrm{Eq} 1)$

Change in Length $=(\mathrm{LI}-\mathrm{LF}) / \mathrm{LI} * 100(\mathrm{Eq} 2)$ 
Thermogravimetric analysis (TGA) was carried out on the control and ANF nanocomposites to analyze their thermal stability using a TGA/DSC 1 STARe System (Mettler Tole-do AG, Analytical-Switzerland) under a nitrogen atmosphere with a heating rate of $10^{\circ} \mathrm{C}$ min 1 from $25-$ $700{ }^{\circ} \mathrm{C}$. Scanning electron microscopy (SEM) images were obtained with the Zeiss-SUPRA 40 SEM (Carl Zeiss Microscopy). The samples were mounted on $15 \mathrm{~mm}$ aluminum stubs using double-sided adhesive copper tape.

\section{RESULTS AND DISCUSSION}

\subsection{ANF Nanocomposite Formulation and 3D Printing}

2-HEA and Genomer 1122 were selected as the matrix, based on their ability to make hydrogen bonds with the amide groups of ANFs. We used a probe sonicator to disperse the ANFs and obtain homogeneous mixtures with the photoresin. We could successfully print photoresins that contain up to $1.5 \mathrm{wt}$ \% ANFs. However, above that concentration, the ANF formulations were no longer a liquid and were not printable. Tensile specimens were printed with these formulations and postprocessed using a solvent exchange and drying procedure to remove unreacted acrylates and solvent. We used water to remove the DMSO from the printed specimens by solvent exchange as it has a lower boiling point and is easier to remove by vacuum drying. We observed that the printed specimens were swollen after the water exchange step. The degree of swelling decreased when the ANF content was higher, indicating improved crosslinking through non-covalent interactions (Figure S3, Table S2). We tested a variety of drying conditions but found in general that it was important to use slower evaporation and longer drying times to obtain samples without cracks or damage. This gradual solvent removal process led to defect-free parts for samples with up to 0.60 wt.\% ANF content (Figure 3b). After these postprocessing steps TGA shows no mass loss up to $200{ }^{\circ} \mathrm{C}$, indicating that the printed parts are solvent-free (Figure S2). Printed objects with 0.80 wt. $\%$ ANFs and above, showed cracks after solvent exchange with DI water (Figure 3b).

\subsection{FT-IR Analysis of ANF Reinforced Nanocomposites}

We studied intermolecular interactions between the ANFs and the polymer matrix (Figure 2A) in our 3D printed nanocomposites by FT-IR. The FT-IR spectrum of the control photoresin (denoted as 0 wt.\% ANF), and the ANF nanocomposites are shown in Figure 2B. The stretching vibration corresponding to the hydroxyl groups in 2-HEA appears as a wide peak at $3400 \mathrm{~cm}^{-1}$ in the control photo-resin and we observed a bathochromic shift in this peak for most of the ANF nanocomposites (Figure 2C). Adding small amounts (0.12 wt.\%) of ANFs was not followed by a notable peak shift, but in the composites above $0.25 \mathrm{wt} \%$ ANFs, a significant shift was observed with increasing amounts of nanofiller (Figure 2B, Table S3). This peak shift is attributed to hydrogen bonding (Figure 2A) between the hydroxyl group of 2-HEA and the N-H groups of the ANFs, which is consistent with previous literature on ANF reinforced composites. ${ }^{40}$ 


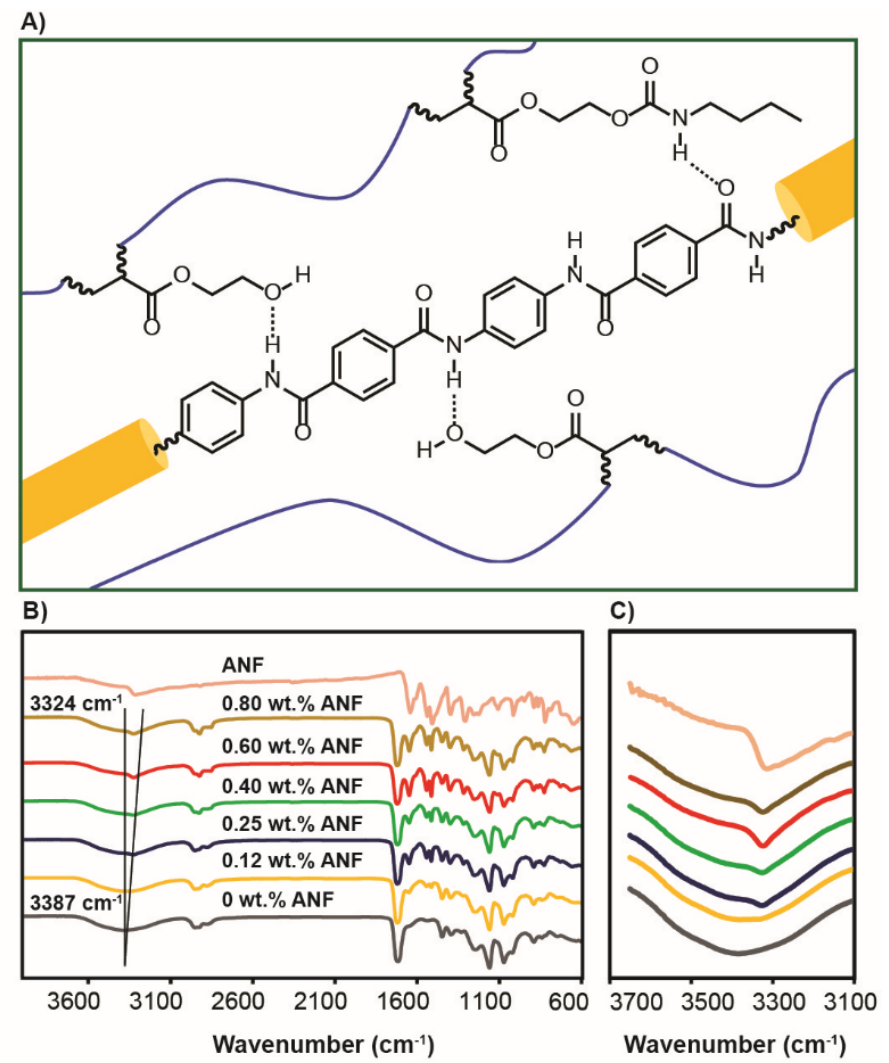

Figure 2. (A) Hydrogen bond formation between ANFs (am-ide groups) and photoresin (hydroxyl groups). (B) FT-IR spectra for control photoresin and nanocomposites with different concentrations of ANFs after 3D printing. (C) Expand-ed hydroxyl stretching region of the control photoresin and the nanocomposites with different concentrations of ANFs after 3D printing.

\subsection{Evaluation of Mechanical Properties}

The mechanical properties of the ANF reinforced nanocomposites were evaluated by tensile tests using 3D printed dogbones (Figure 3A and 3B). Low concentrations of ANFs did not show a notable change in ultimate tensile strength (UTS). By reinforcing with 0.12 wt. $\%$ ANF, the UTS increased only by $3 \%$, but it increased up to $24 \%$ after adding $0.25 \mathrm{wt} . \%$ ANF (Figure 3C). The maximum tensile strength observed is for the $0.60 \mathrm{wt} . \%$ ANF resin formulation, which resulted in $4.20( \pm 0.21) \mathrm{MPa}$ with an enhancement of $265 \%$ compared to the control resin. After this point (above $0.60 \%$ ), increasing ANF content reduced the UTS. This is attributed to the formation of cracks or defects in these higher ANF loading composites that could not be eliminated. For the 0.12 wt. $\%$ ANF nanocomposite the toughness increased by $18 \%$. The 0.60 wt. $\%$ ANF nanocomposite had the highest toughness value of $4.8 \pm 0.7 \mathrm{MJ} / \mathrm{m} 3$, which is a $219 \%$ increase com-pared to the control photoresin (Figure 3D). 

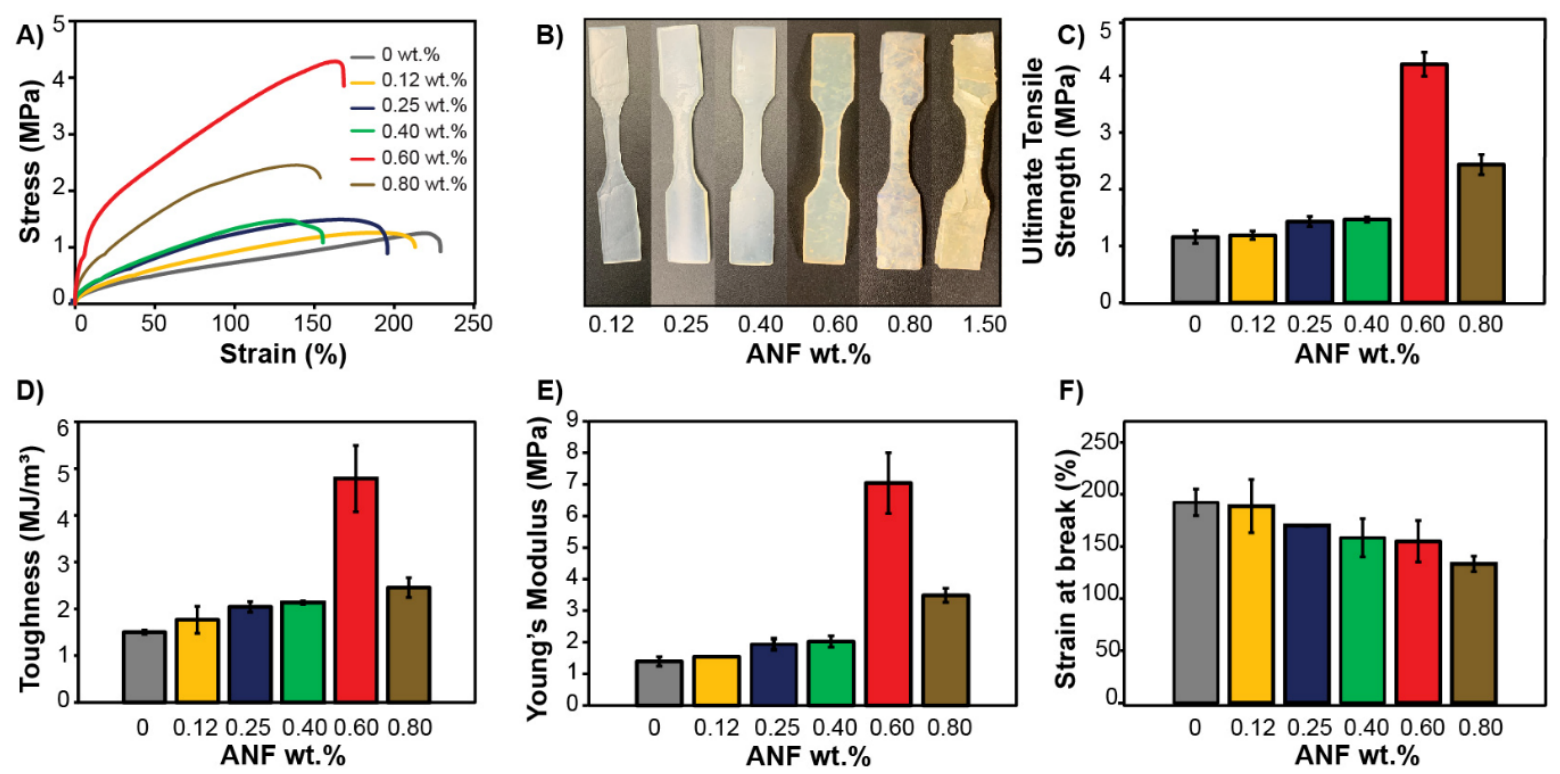

Figure 3. Evaluation of mechanical properties of the control photoresin and the ANF nanocomposites. (A) SLA printed tensile specimens of nanocomposites with different concentrations of ANFs (B) Representative stress-strain curves (C) Ultimate tensile strength (D) Toughness (E) Young's modulus (F) Strain at break of the control photoresin and nanocomposites with different concentrations of ANFs.

Table 1: Mechanical property values of the control and the ANF nanocomposites.

\begin{tabular}{|c|c|c|c|c|c|c|c|}
\hline ANF Wt.\% & UTS (MPa) & $\begin{array}{c}\text { \% Increase in } \\
\text { UTS vs } \\
\text { control }\end{array}$ & $\begin{array}{c}\text { Toughness } \\
\left(\mathbf{M J} / \mathbf{m}^{3}\right)\end{array}$ & $\begin{array}{c}\text { \% Increase in } \\
\text { toughness vs } \\
\text { control }\end{array}$ & $\begin{array}{c}\text { Young's } \\
\text { modulus } \\
(\mathrm{MPa})\end{array}$ & $\begin{array}{c}\text { \% Increase in } \\
\text { Young's } \\
\text { modulus vs } \\
\text { control }\end{array}$ & $\begin{array}{c}\text { Strain at break } \\
(\%)\end{array}$ \\
\hline $\mathbf{0}$ & $1.15( \pm 0.11)$ & N/A & $1.50( \pm 0.05)$ & N/A & $1.39( \pm 0.15)$ & N/A & $192.42( \pm 12.70)$ \\
\hline 0.25 & $1.43( \pm 0.09)$ & 24 & $2.04( \pm 0.11)$ & 36 & $1.94( \pm 0.17)$ & 39 & $170.18( \pm 0.50)$ \\
\hline 0.40 & $1.46( \pm 0.04)$ & 27 & $2.13( \pm 0.04)$ & 42 & $2.02( \pm 0.18)$ & 45 & $158.32( \pm 18.37)$ \\
\hline 0.60 & $4.20( \pm 0.21)$ & 265 & $4.79( \pm 0.71)$ & 219 & $7.04( \pm 0.96)$ & 406 & $154.96( \pm 19.90)$ \\
\hline 0.80 & $2.43( \pm 0.18)$ & 111 & $2.46( \pm 0.21)$ & 64 & $3.49( \pm 0.22)$ & 150 & $133.38( \pm 7.35)$ \\
\hline
\end{tabular}

For the 0.80 wt.\% ANF nanocomposite toughness was $2.46 \mathrm{MJ} / \mathrm{m} 3$, which is lower than the toughness obtained from the $0.60 \mathrm{wt} . \%$ nanocomposite, yet it is still $64 \%$ better than the control photoresin. A similar trend was observed for the Young's modulus. When increasing the ANF 
content the Young's modulus increased gradually (Figure 3E), and the maximum value was observed for the $0.60 \mathrm{wt}$. \% nanocomposite, with $7.04 \pm 0.96 \mathrm{MPa}$ yielding an improvement of $406 \%$ compared to the control. The highest strain at break value was observed for the control photoresin which had a value of $192 \%$ and loading ANFs into the photoresins resulted in a gradual reduction in strain at break to $133 \%$ (Figure $3 \mathrm{~F}$ ).

The results after the incorporation of the ANFs show how the 2-HEA matrix can successfully transfer stress to the ANF filler upon tension. This demonstrates the ability of ANFs to be an effective nanofiller for photo-printable resins. Dispersion of ANFs in the photoresin is challenging at higher ANF concentrations due to the formation of voids and agglomerations. These factors affect mechanical properties of the fiber composites after a specific thresh-old value. We observed cracking (Figure 3B) on these samples (above $0.60 \mathrm{wt}$ \%) after the post-processing steps and the SEM images up to $0.60 \mathrm{wt}$. \% show homogeneous surfaces but we observed cracked surfaces for $0.80 \mathrm{wt} \%$ ANF nanocomposites (Figure S4). This might be due to the increased stiffness we observed in high wt.\% ANF composites, which increases the possibility of cracking upon swelling or deswelling.

Toughness and tensile strength are often considered to be mutually exclusive as intrinsic properties in polymeric materials.30,31 Many nanocomposites have a trade-off effect due to the reduction in strain at break, which is a result of high crosslinking density and a plasticizing effect from the filler, ${ }^{26,41}$ that limits the final performance of the material. In this study both strength and toughness in-creased simultaneously, potentially due to the hydrogen bonding between the matrix and the filler.

\subsection{Shape Stability and the Printability of ANF Nanocomposites}

We printed a complex structure (a Vesak lantern) with 0.60 wt.\% ANF nanocomposite and postprocessed it to examine its shape stability (Figure 4A). As shown in Figure 4B, we could successfully maintain the printed structural features with a minimum amount of length variation after post-processing.

A)
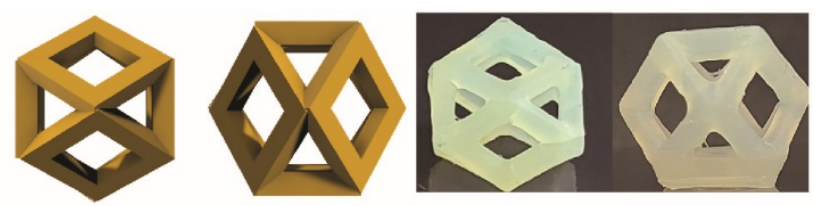

B)
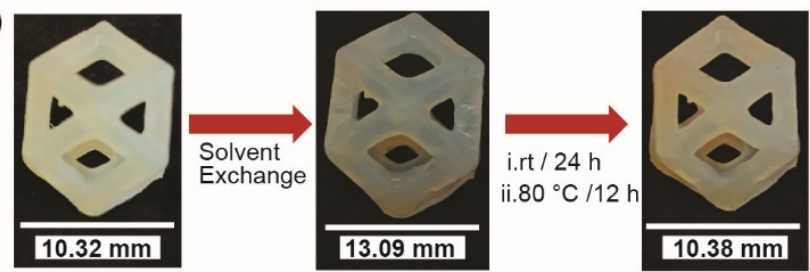

Figure 4. (A) Digital designs and the SLA printed $0.60 \mathrm{wt} . \%$ ANF nanocomposite structures (B) As printed Vesak lantern, after solvent exchange in DI water for $12 \mathrm{~h}$, and after drying. White scale bars represent the length of the Vesak lantern. 
Dimensional variations (change in the length, width, and thickness) were evaluated using 3D printed rectangles for before and after post-processing method. All the formulations showed a decrease in length and width compared to the original printed specimens (before post-processing). Overall, higher loadings of ANFs caused greater changes in the printed part's dimensions after post processing (Figure $\mathrm{S} 1$ ).

\section{CONCLUSION}

We developed a post-processing technique that enables the incorporation of ANFs into a photoresin that can be 3D printed via SLA. We could print ANF nanocomposites with loadings up to $1.50 \mathrm{wt} . \%$ and defect-free printed parts were obtained in loadings up to $0.60 \mathrm{wt} . \%$. The mechanical properties including ultimate tensile strength, toughness as well as the Young's modulus were increased for ANF loadings up to $0.60 \mathrm{wt} . \%$, but above that concentration we observed reduced mechanical properties which likely arise from defects that form in the printed parts during the post- processing. This study highlights the capacity of ANFs as a nanoscale reinforcement of photo-resins in enhancing mechanical properties without compromising printability. Our future work in this area aims to use this post-processing methodology to create new photo printable nanocomposites, as well as developing new resin formulations that can enable printing of ANF composites with even higher loading.

\section{ACKNOWLEDGMENT}

We acknowledge previous support from the Department of Energy's National Nuclear Security Agency, managed by Honeywell FM\&T (N000263171) and the Army Research Laboratory (W911NF-18-2-0035). A.D.S. acknowledges the Consejo Nacional de Ciencia y Tecnología (CONACYT, Mexican Council of Science and Technology) for doctoral fellowship. We also acknowledge the Advanced Polymer Research Lab (APRL) at UT Dallas for technical assistance.

EMAIL: ronald.smaldone@utdallas.edu

\section{REFERENCES}

(1) Ligon, S. C.; Liska, R.; Stampfl, J.; Gurr, M.; Mülhaupt, R. Polymers for 3D Printing and Customized Additive Manufacturing. Chem. Rev. 2017, 117, 10212-10290.

(2) Ngo, T. D.; Kashani, A.; Imbalzano, G.; Nguyen, K. T. Q.; Hui, D. Additive Manufacturing (3D Printing): A Review of Materials, Methods, Applications and Challenges. Compos. Part B Eng. 2018, 143, 172-196.

(3) Berry, D. R.; Cortés-Guzmán, K. P.; Durand-Silva, A.; Perera, S. D.; Remy, A. K.; Yan, Q.; Smaldone, R. A. Supramolecular Tools for Polymer Additive Manufacturing. MRS Commun. 2021, $11,1-11$.

(4) Yu, C.; Schimelman, J.; Wang, P.; Miller, K. L.; Ma, X.; You, S.; Guan, J.; Sun, B.; Zhu, W.; Chen, S. Photopolymerizable Biomaterials and Light-Based 3D Printing Strategies for Biomedical Applications. Chem. Rev. 2020, 120, 10695-10743.

(5) Bagheri, A.; Jin, J. Photopolymerization in 3D Printing. ACS Appl. Polym. Mater. 2019, 1, 593-611.

(6) Monti, J.; Blasco, E. Hierarchical Ordering in Light-Triggered Additive Manufacturing. Polym. Chem. 2020, 11, 7316-7329. 
(7) Appuhamillage, G. A.; Chartrain, N.; Meenakshisundaram, V.; Feller, K. D.; Williams, C. B.; Long, T. E. 110th Anniversary: Vat Photopolymerization-Based Additive Manufacturing: Current Trends and Future Directions in Materials Design. Ind. Eng. Chem. Res. 2019, 58, 1510915118.

(8) Durand-Silva, A.; Cortés-Guzmán, K. P.; Johnson, R. M.; Perera, S. D.; Diwakara, S. D.; Smaldone, R. A. Balancing Self-Healing and Shape Stability in Dynamic Covalent Photoresins for Stereolithography 3D Printing. ACS Macro Lett. 2021, 10, 486-491.

(9) Yee, D. W.; Greer, J. R. Three-Dimensional Chemical Reactors: In Situ Materials Synthesis to Advance Vat Photopolymerization. Polym. Int. 2021, 70, 964-976.

(10) Wang, X.; Jiang, M.; Zhou, Z.; Gou, J.; Hui, D. 3D Printing of Polymer Matrix Composites: A Review and Prospective. Compos. Part B Eng. 2017, 110, 442-458.

(11) Parandoush, P.; Lin, D. A Review on Additive Manufacturing of Polymer-Fiber Composites. Compos. Struct. 2017, 182, 36-53.

(12) Karalekas, D.; Antoniou, K. Composite Rapid Prototyping: Overcoming the Drawback of Poor Mechanical Properties. J. Mater. Process. Technol. 2004, 153-154, 526-530.

(13) Patel, A.; Taufik, M. Nanocomposite Materials for Fused Filament Fabrication. Mater. Today Proc. 2021, in press. https://doi.org/10.1016/j.matpr.2021.05.438.

(14) Sano, Y.; Matsuzaki, R.; Ueda, M.; Todoroki, A.; Hirano, Y. 3D Printing of Discontinuous and Continuous Fibre Composites Using Stereolithography. Addit. Manuf. 2018, 24, 521-527.

(15) Kalsoom, U.; Nesterenko, P. N.; Paull, B. Recent Developments in 3D Printable Composite Materials. RSC Adv. 2016, 6, 60355-60371.

(16) Nasser, J.; Zhang, L.; Lin, J.; Sodano, H. Aramid Nanofiber Reinforced Polymer Nanocomposites via Amide-Amide Hydrogen Bonding. ACS Appl. Polym. Mater. 2020, 2, 29342945.

(17) Suryanegara, L.; Nakagaito, A. N.; Yano, H. The Effect of Crystallization of PLA on the Thermal and Mechanical Properties of Microfibrillated Cellulose-Reinforced PLA Composites. Compos. Sci. Technol. 2009, 69, 1187-1192.

(18) Maldas, D.; Kokta, B. V.; Daneault, C. Influence of Coupling Agents and Treatments on the Mechanical Properties of Cellulose Fiber-Polystyrene Composites. J. Appl. Polym. Sci. 1989, 37, 751-775.

(19) Palaganas, N. B.; Mangadlao, J. D.; De Leon, A. C. C.; Palaganas, J. O.; Pangilinan, K. D.; Lee, Y. J.; Advincula, R. C. 3D Printing of Photocurable Cellulose Nanocrystal Composite for Fabrication of Complex Architectures via Stereolithography. ACS Appl. Mater. Interfaces 2017, 9 , 34314-34324.

(20) Kumar, S.; Hofmann, M.; Steinmann, B.; Foster, E. J.; Weder, C. Reinforcement of Stereolithographic Resins for Rapid Prototyping with Cellulose Nanocrystals. ACS Appl. Mater. Interfaces 2012, 4, 5399-5407.

(21) Mathur, R. B.; Chatterjee, S.; Singh, B. P. Growth of Carbon Nanotubes on Carbon Fibre Substrates to Produce Hybrid/Phenolic Composites with Improved Mechanical Properties. Compos. Sci. Technol. 2008, 68, 1608-1615.

(22) Jiang, X.; Bin, Y.; Matsuo, M. Electrical and Mechanical Properties of Polyimide-Carbon Nanotubes Composites Fabricated by in Situ Polymerization. Polymer (Guildf). 2005, 46, 74187424.

(23) Zhang, Q.; Liu, J.; Sager, R.; Dai, L.; Baur, J. Hierarchical Composites of Carbon Nanotubes on Carbon Fiber: Influence of Growth Condition on Fiber Tensile Properties. Compos. Sci. Technol. 2009, 69, 594-601. 
(24) Chen, Q.; Mangadlao, J. D.; Wallat, J.; De Leon, A.; Pokorski, J. K.; Advincula, R. C. 3D Printing Biocompatible Polyurethane/Poly(Lactic Acid)/Graphene Oxide Nanocomposites: Anisotropic Properties. ACS Appl. Mater. Interfaces 2017, 9, 4015-4023.

(25) Medhekar, N. V.; Ramasubramaniam, A.; Ruoff, R. S.; Shenoy, V. B. Hydrogen Bond Networks in Graphene Oxide Composite Paper: Structure and Mechanical Properties. ACS Nano 2010, 4, 2300-2306.

(26) Jayan, J. S.; Pal, K.; Saritha, A.; Deeraj, B. D. S.; Joseph, K. Graphene Oxide as MultiFunctional Initiator and Effective Molecular Reinforcement in PVP/Epoxy Composites. J. Mol. Struct. 2021, 1230, 129873.

(27) Weng, Z.; Wang, J.; Senthil, T.; Wu, L. Mechanical and Thermal Properties of ABS/Montmorillonite Nanocomposites for Fused Deposition Modeling 3D Printing. Mater. Des. 2016, 102, 276-283.

(28) Ramirez-Soria, E. H.; Bonilla-Cruz, J.; Flores-Amaro, M. G.; Garcia, V. J.; Lara-Ceniceros, T. E.; Longoria-Rodriguez, F. E.; Elizondo, P.; Advincula, R. C. On the Effect of Ultralow Loading of Microwave-Assisted Bifunctionalized Graphene Oxide in Stereolithographic 3d-Printed Nanocomposites. ACS Appl. Mater. Interfaces 2020, 12, 49061-49072.

(29) Yang, M.; Cao, K.; Sui, L.; Qi, Y.; Zhu, J.; Waas, A.; Arruda, E. M.; Kieffer, J.; Thouless, M. D.; Kotov, N. A. Dispersions of Aramid Nanofibers: A New Nanoscale Building Block. $A C S$ Nano 2011, 5, 6945-6954.

(30) Guan, Y.; Li, W.; Zhang, Y.; Shi, Z.; Tan, J.; Wang, F.; Wang, Y. Aramid Nanofibers and Poly (Vinyl Alcohol) Nanocomposites for Ideal Combination of Strength and Toughness via Hydrogen Bonding Interactions. Compos. Sci. Technol. 2017, 144, 193-201.

(31) Zhu, J.; Cao, W.; Yue, M.; Hou, Y.; Han, J.; Yang, M. Strong and Stiff Aramid Nanofiber/Carbon Nanotube Nanocomposites. ACS Nano 2015, 9, 2489-2501.

(32) Kwon, S. R.; Harris, J.; Zhou, T.; Loufakis, D.; Boyd, J. G.; Lutkenhaus, J. L. Mechanically Strong Graphene/Aramid Nanofiber Composite Electrodes for Structural Energy and Power. ACS Nano 2017, 11, 6682-6690.

(33) Xu, L.; Zhao, X.; Xu, C.; Kotov, N. A. Water-Rich Biomimetic Composites with Abiotic Self-Organizing Nanofiber Network. Adv. Mater. 2018, 30, 1-6.

(34) Lin, J.; Bang, S. H.; Malakooti, M. H.; Sodano, H. A. Isolation of Aramid Nanofibers for High Strength and Toughness Polymer Nanocomposites. ACS Appl. Mater. Interfaces 2017, 9, 11167-11175.

(35) Guo, Y.; An, X.; Fan, Z. Aramid Nanofibers Reinforced Polyvinyl Alcohol/Tannic Acid Hydrogel with Improved Mechanical and Antibacterial Properties for Potential Application as Wound Dressing. J. Mech. Behav. Biomed. Mater. 2021, 118, 104452.

(36) Li, Y.; Dai, R.; Zhou, H.; Li, X.; Wang, Z. Aramid Nanofiber Membranes Reinforced by MXene Nanosheets for Recovery of Dyes from Textile Wastewater. ACS Appl. Nano Mater. 2021, 4, 6328-6336.

(37) Lyu, J.; Liu, Z.; Wu, X.; Li, G.; Fang, D.; Zhang, X. Nanofibrous Kevlar Aerogel Films and Their Phase-Change Composites for Highly Efficient Infrared Stealth. ACS Nano 2019, 13, $2236-2245$.

(38) Nurulhuda, A.; Sudin, I.; Ngadiman, N. H. A. Fabrication a Novel 3D Tissue Engineering Scaffold of Poly (Ethylene Glycol) Diacrylate Filled with Aramid Nanofibers via Digital Light Processing (DLP) Technique. J. Mech. Eng. 2020, 9, 1-12. 
(39) Lyu, J.; Hammig, M. D.; Liu, L.; Xu, L.; Chi, H.; Uher, C.; Li, T.; Kotov, N. A. Stretchable Conductors by Kirigami Patterning of Aramid-Silver Nanocomposites with Zero Conductance Gradient. Appl. Phys. Lett. 2017, 111, 161901.

(40) Xiong, S.; Zhang, C.; Huang, R.; Luo, K.; Zhu, X.; Tong, G. Strong yet Tough, Excellent Thermal Resistant and UV-Protective Polydopamine/Poly(Vinyl Alcohol) Composites via Hydrogen-Bonding Interaction. Polymer 2021, 221, 123603.

(41) Wei, J.; Jia, S.; Wei, J.; Ma, C.; Shao, Z. Tough and Multifunctional Composite Film Actuators Based on Cellulose Nanofibers toward Smart Wearables. ACS Appl. Mater. Interfaces 2021, 13, 38700-38711. 


\section{Supplementary Information}

\section{D Printing of Aramid Nanofiber Composites by Stereolithography}

Sachini D. Perera, Alejandra Durand-Silva, Ashele K. Remy, Shashini D. Diwakara, Ronald A. Smaldone*

Department of Chemistry and Biochemistry University of Texas, Dallas

800 W. Campbell Rd. Richardson, TX, 75080

*Correspondence Address

Professor Ronald A. Smaldone

Department of Chemistry and Biochemistry

The University of Texas at Dallas

800 W. Campbell Road

Richardson, Texas 75080

Phone: (+1)-972-883-6342

email: ronald.smaldone@utdallas.edu

\section{Table of contents}

1. Table for formulations and degree of swelling of ANF nanocomposites ...........................2

2. FT-IR peak shift and shape stability evaluation of ANF nanocomposites ...........................

3. Thermogravimetric analysis, degree of swelling and SEM images of ANF nanocomposites ...........4 


\section{Formulation, degree of swelling and IR peak shift for ANF nanocomposites}

Table 1: Formulations of ANF resins

\begin{tabular}{|c|c|c|c|c|c|}
\hline Formulation & $\begin{array}{c}\text { ANF } \\
\text { wt. \% }\end{array}$ & ANF $(\mathrm{g})$ & $\begin{array}{c}\text { HEA } \\
(\mathrm{g})\end{array}$ & $\begin{array}{c}\text { PEGDA( } \\
\mathrm{g})\end{array}$ & $\begin{array}{c}\text { Genomer } \\
(\mathrm{g})\end{array}$ \\
\hline $\mathrm{ANF}_{0}$ & 0 & 0 & 19.31 & 0.69 & 0.50 \\
\hline $\mathrm{ANF}_{0.12}$ & 0.12 & 1.30 & 19.31 & 0.69 & 0.50 \\
\hline $\mathrm{ANF}_{0.25}$ & 0.25 & 2.90 & 19.31 & 0.69 & 0.50 \\
\hline $\mathrm{ANF}_{0.40}$ & 0.40 & 5.10 & 19.31 & 0.69 & 0.50 \\
\hline $\mathrm{ANF}_{0.60}$ & 0.60 & 8.70 & 19.31 & 0.69 & 0.50 \\
\hline $\mathrm{ANF}_{0.80}$ & 0.80 & 13.60 & 19.31 & 0.69 & 0.50 \\
\hline
\end{tabular}

Table 2: The degree of swelling of ANF nanocomposites

\begin{tabular}{|c|c|}
\hline Formulation & Degree of swelling (\%) \\
\hline $\mathrm{ANF}_{0}$ & $159.9( \pm 5.8)$ \\
\hline $\mathrm{ANF}_{0.12}$ & $142.4( \pm 3.8)$ \\
\hline $\mathrm{ANF}_{0.25}$ & $138.1( \pm 4.8)$ \\
\hline $\mathrm{ANF}_{0.40}$ & $133.9( \pm 4.2)$ \\
\hline $\mathrm{ANF}_{0.60}$ & $92.5( \pm 6.2)$ \\
\hline $\mathrm{ANF}_{0.80}$ & $98.2( \pm 6.1)$ \\
\hline
\end{tabular}




\section{FT-IR peak shift and shape stability evaluation of ANF nanocomposites}

Table 3: Maximum shift in N-H Stretching Vibration Bands occurred in neat and ANF Reinforced nanocomposites under FT-IR.

\begin{tabular}{|c|c|}
\hline Formulation & Wave number $\left(\mathrm{cm}^{-1}\right)$ \\
\hline $\mathrm{ANF}_{0}$ & 3386 \\
\hline $\mathrm{ANF}_{0.12}$ & 3383 \\
\hline $\mathrm{ANF}_{0.25}$ & 3327 \\
\hline $\mathrm{ANF}_{0.40}$ & 3327 \\
\hline $\mathrm{ANF}_{0.60}$ & 3325 \\
\hline $\mathrm{ANF}_{0.80}$ & 3325 \\
\hline
\end{tabular}

A)

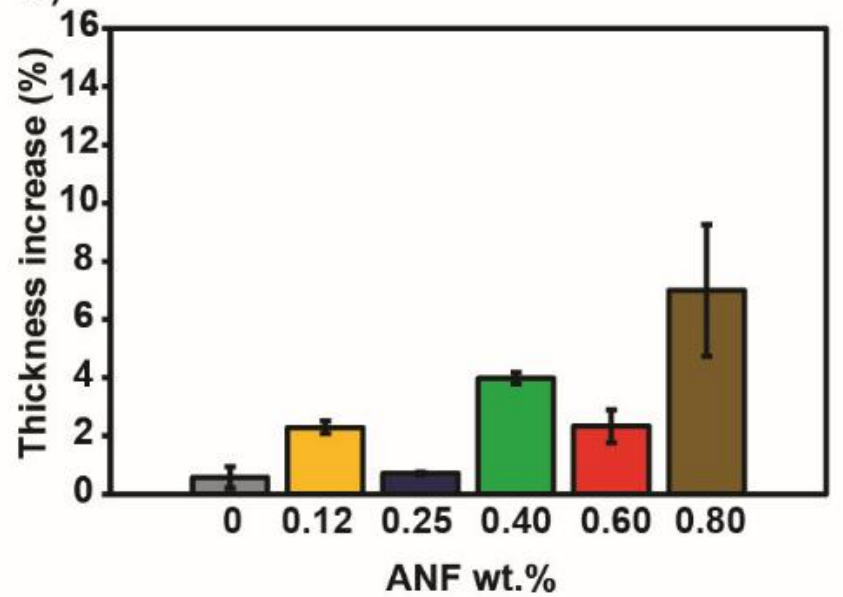

C)
B)

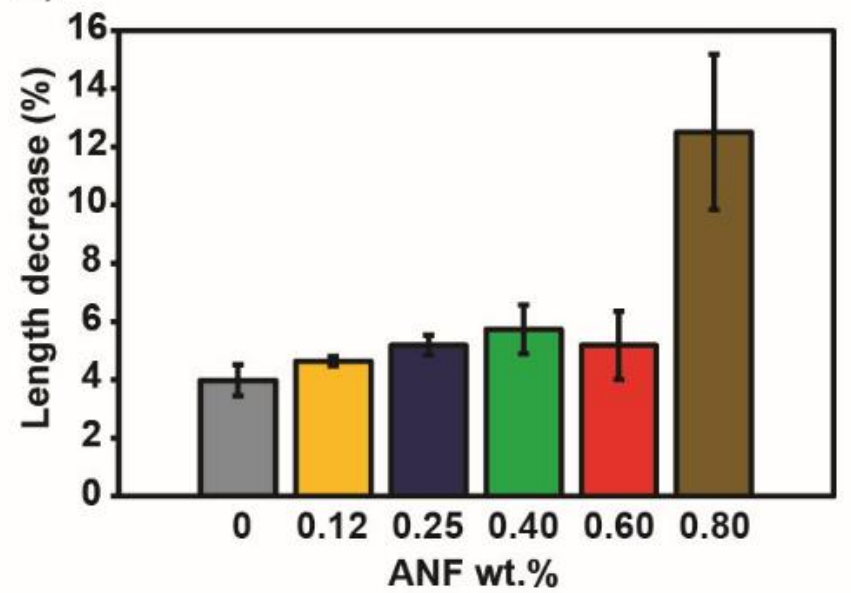

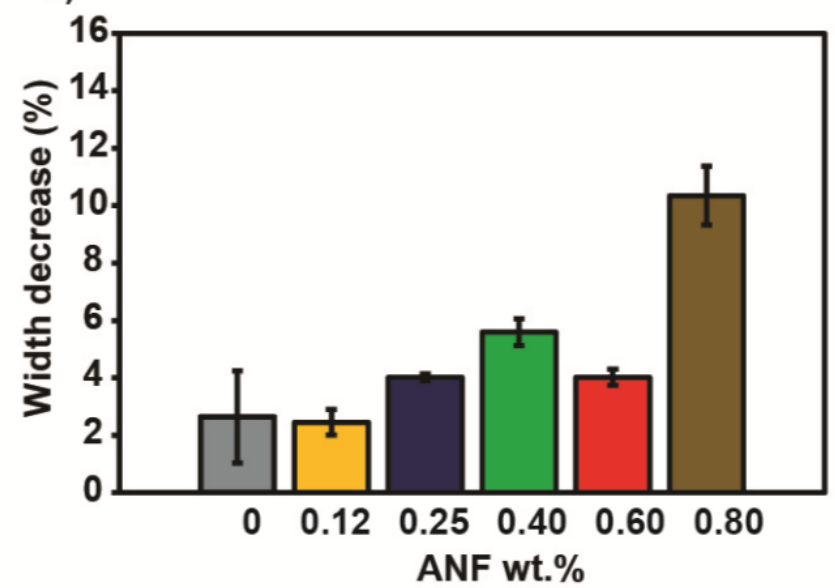

Figure S1: Dimensional stability after post processing. The change in (a) length, (b)width, and (c) thickness. 


\section{Thermogravimetric analysis, degree of swelling and SEM images of ANF nanocomposites}

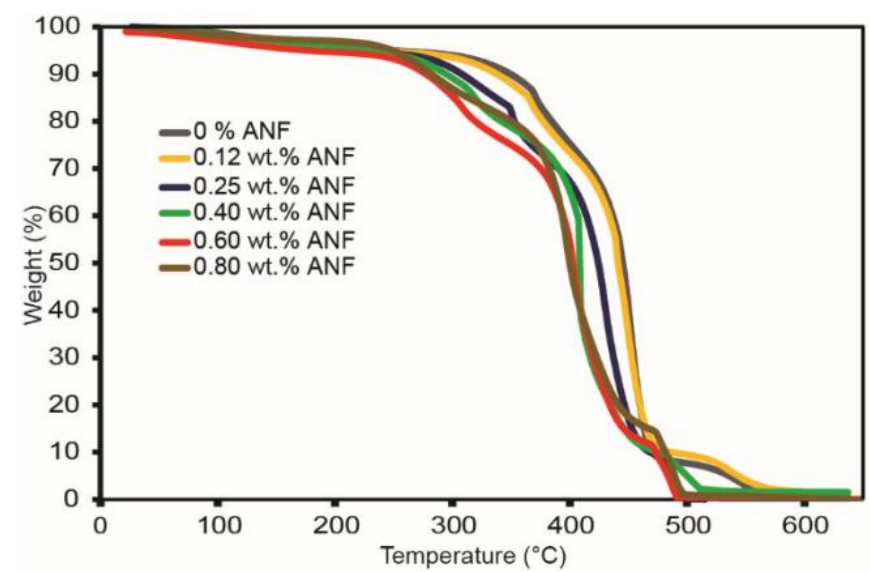

Figure S2: Thermogravimetric analysis of ANF nanocomposites.

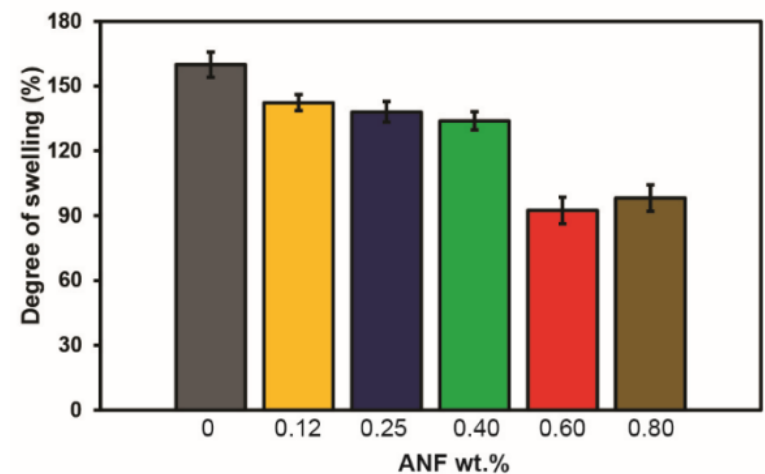

Figure S3: (a) Degree of swelling of the control and ANF nanocomposites.

a)

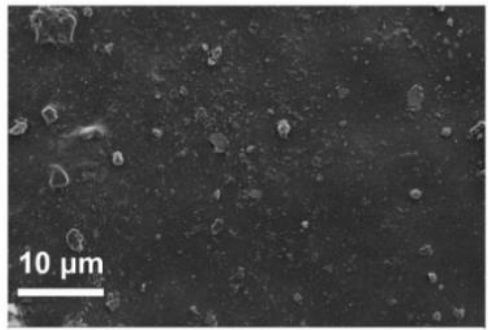

d)

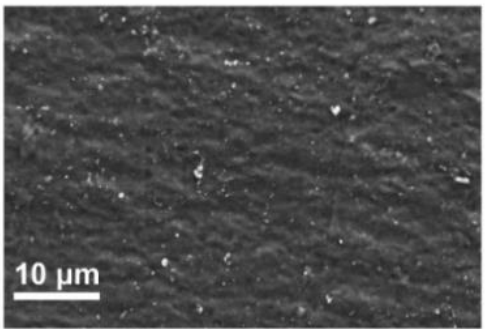

b)

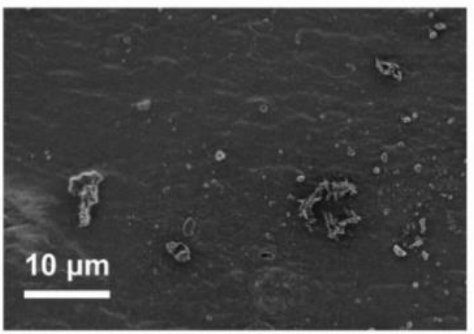

e)

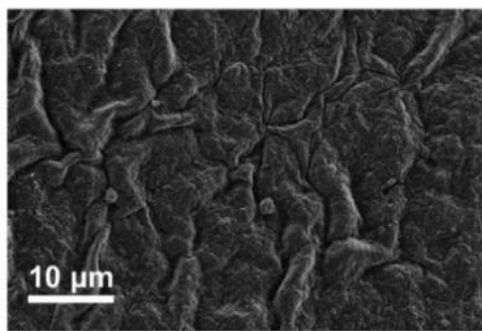

c)

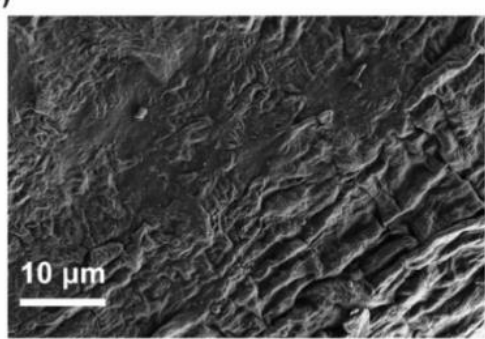

f)

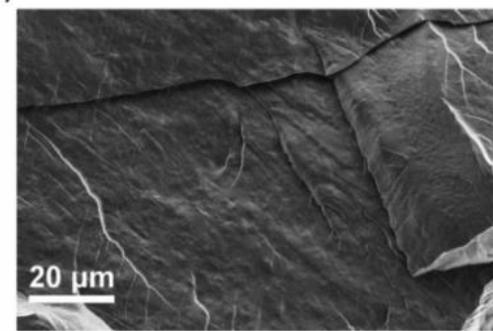

Figure S4: SEM images of a) 0 wt.\% ANF b) 0.12 wt.\% ANF c) 0.25 wt.\% ANF d) 0.40 wt.\% ANF e) 0.60 wt.\% ANF f) 0.80 wt.\% ANF nanocomposites 